\title{
DESPATOLOGIZAÇÃO DO GÊNERO: A POLITIZAÇÃO DAS IDENTIDADES ABJETAS
}

\author{
Berenice Bento \\ Universidade Federal do Rio Grande do Norte \\ Larissa Pelúcio \\ Universidade Estadual Paulista, Bauru
}

\begin{abstract}
Resumo: Apesar das mudanças políticas e sociais em relação às transexualidades e travestilidades, elas ainda são consideradas pela Associação de Psiquiatria Norte-Americana (APA) e pela Organização Mundial da Saúde (OMS) como transtornos mentais. Essas entidades divulgarão em 2013 as novas versões do Manual Diagnóstico e Estatístico de Transtornos Mentais (DSM - APA) e do Código Internacional de Doença (CID - OMS), o que tem mobilizado ativistas trans que reivindicam a retirada da transexualidade do rol das doenças identificáveis como transtornos mentais. A campanha Stop Trans Pathologization (Pare a Patologização!) se internacionalizou e envolvia, até o início de 2012, mais de 29 países. Neste artigo, discutiremos algumas iniciativas dessa campanha, analisaremos a ideologia de gênero presente no DSM e no CID, que incorporam o gênero como uma categoria diagnóstica, e, por fim, apresentaremos argumentos pelo fim do diagnóstico de gênero.

Palavras-chave: identidades trans; campanha Pare a Patologização!; gênero e sexualidade.
\end{abstract} "Você usa rosa ou você usa azul? Você tem pinto ou você tem buceta? Você usa shorts
e fica brincando de Homem-Aranha ou você tem que ficar penteando o cabelo de
uma Barbie? Cada ser humano tem as suas verdades, tem as coisas as quais tem que
buscar e realizar. Alguns seres simplesmente têm uma incompatibilidade sexual
com o corpo, Isso não é uma transformação, isso é um fato. Você nasceu mulher,
mas você é um homem. Aí você se pega tendo que fazer da sua vida uma
transformação inteira porque todo mundo quer que seja."

Daniela Glamour Garcia, depoimento à Camila BIAU, 2011.

Daniela Glamour Garcia olha para a câmera com olhos inquietos. Está visivelmente sensibilizada pelos meses em que esteve protagonizando um documentário sobre

Copyright ๑ 2012 by Revista Estudos Feministas. 
identidades sexuais a partir de uma perspectiva queer. ${ }^{1}$ Dani, como gosta de ser chamada, se sente incompreendida, mas nunca doente, patologizável, curável. Daniela gostaria de não ter de pensar o tempo todo em sua sexualidade, em seu corpo, em seus desejos. Participar do documentário Além das sete cores, dirigido por Camila Biau, ${ }^{2}$ tornou essas reflexões prementes, presentes e um tanto opressivas. Daniela, que inicia as filmagens coreografando passos pela Rua Augusta, no coração da capital paulista, mas chega ao final do filme visivelmente sensibilizada. Sua última fala registra sua busca por termos de identificação que possam tornar sua vida habitável, fora dos referentes patologizantes e psicologizantes hoje disponíveis. Naquela última cena, Dani parece estar cansada dessa luta; talvez por isso, ao fim de sua participação no documentário, tenha iniciado o processo transexualizador, oferecido pelo Hospital das Clínicas, em São Paulo. Foi buscar nos discursos médicos e psi (referentes à psicanálise, psicologia e psiquiatria) os termos de sua busca por inteligibilidade.

A história de Daniela Garcia nos ajuda a iniciar a discussão que alicerça este artigo: apresentar e discutir algumas iniciativas da campanha internacional pela despatologização das identidades sexuais; fazer uma leitura dos manuais médicos e psiquiátricos que incorporam o gênero como uma categoria diagnóstica; e, por fim, apresentar argumentos pelo fim do diagnóstico de gênero.

Começamos pelas questões necessárias: como o gênero tornou-se uma categoria diagnóstica? Quais as consequências desse processo para pessoas que, como Daniela, questionam com sua experiência os binarismos de macho/fêmea, homem/mulher, cultura/ natura e, por consequência, desafiam as classificações patologizantes das sexualidades que estão em desacordo com a norma heterossexual? Mais que resposta a essas perguntas, buscamos oferecer elementos que permitam às leitoras e aos leitores dimensionar o peso dos discursos que constituíram certas existências como "anormais", estabelecendo modelos de suposta coerência entre sexo biológico e gênero cultural como marco de normalidade e saúde. Iniciamos, então, apresentando alguns desses momentos de inflexão na construção desses discursos e nos esforços universalizantes empreendidos por determinadas áreas de saber para a consolidação de verdades sobre os corpos, os gêneros e os desejos.

\section{O gênero como categoria diagnóstica}

Na década de 1950 foram publicados os primeiros artigos que registraram e defenderam a especificidade do "fenômeno transexual". Mas desde o início daquela década o endocrinologista Harry Benjamin se dedicava a estabelecer as ocorrências que justificariam a diferenciação das pessoas transexuais em relação às homossexualidades. A relação de abjeção que as pessoas transexuais têm com as genitálias seria uma das frequências observadas nos seus discursos. Ainda que Benjamin tenha defendido a cirurgia de transgenitalização como a única alternativa terapêutica possível para as pessoas transexuais, estabelece critérios tomados por ele como científicos para que seja possível diagnosticar "o verdadeiro transexual" e assim autorizar a intervenção. Em seu livro $O$ fenômeno transexual, publicado em 1966, ele fornece as bases para esse diagnóstico.

\footnotetext{
I Os estudos queer buscam deslocar a questão da sexualidade e do gênero as identidades dos sujeitos, focando seu interesse investigativo nos discursos de aber que constituíram determinadas existências como menos legítimas que outras, atalogizando comportamento, criminalizando práticas e desejos a partir da aturalização/legitimação da heterossexualidade.

2 Documentário realizado como projeto de conclusão do curso de Rádio e Televisão, pela Universidade Estadual Paulista Júlio de Mesquita Filho, campus Bauru, com 20 minutos, em 2011.
} 
O critério fundamental para definir o "transexual de verdade" seria a relação de abjeção, de longa duração, com suas genitálias. Para evitar que cometam suicídio, as cirurgias deveriam ser recomendadas a partir de um rol de procedimentos arrolados por Benjamin em sua obra seminal.

Essa posição contrapunha-se à dos profissionais da psicologia, psiquiatria e psicanálise, sempre reticentes às intervenções corporais como alternativas terapêuticas. Muitos psicanalistas consideraram esse procedimento como mutilações. Benjamin, ao contrário, afirmava que para "o transexual de verdade" psicoterapias eram inúteis. Nesses casos, apenas as cirurgias poderiam representar a solução para as "enfermidades" daqueles que têm abjeção ao corpo.

A tendência cirúrgica intensificou-se ao longo das décadas de 1960 e 1970, ao mesmo tempo se produziam indicadores que sugeririam onde deveria ser buscado o diagnóstico para diferenciar transexuais de gays, lésbicas e travestis. Nesse marco, em 1969, realizou-se, em Londres, o primeiro congresso da Associação Harry Benjamin, que passou a se chamar Harry Benjamin International Gender Dysphoria Association (HBIGDA), em 1977. A transexualidade passou a ser considerada uma "disforia de gênero", termo cunhado por John Money em 1973. ${ }^{3}$

A Associação publica e revisa regularmente o Standards of Care (SOC). O propósito principal desse documento é articular um consenso profissional internacional acerca do manejo psiquiátrico, psicológico, médico e cirúrgico das "Desordens da Identidade de Gênero". Ao mesmo tempo objetiva orientar os profissionais no entendimento dos "parâmetros dentro dos quais podem oferecer assistência às pessoas com este tipo de problema". ${ }^{4}$

O desejo em produzir um diagnóstico diferenciado para transexuais, anunciado precariamente na década de 1960, ganhou concretude nos anos 1980 . A sua inclusão no Código Internacional de Doenças, em 1980, foi um marco no processo de definição da transexualidade como uma doença.

Foi naquele mesmo ano que a Associação de Psiquiatria Norte-Americana aprovou a terceira versão do Manual Diagnóstico e Estatístico de Transtornos Mentais, incluindo a transexualidade no rol dos "Transtornos de Identidade de Gênero". O mesmo documento, em sua quarta versão, estabeleceu os critérios diagnósticos para as chamadas "perturbações mentais, incluindo componentes descritivos, de diagnóstico e de tratamento, constituindo um instrumento de trabalho de referência para os profissionais da saúde mental em todo o mundo". 5

Encontramos no DSM-IV uma radical defesa do dimorfismo. As performances de gênero, a sexualidade e a subjetividade são níveis constitutivos da identidade do sujeito que se apresentam colados uns aos outros. O masculino e o feminino só se encontram por intermédio da complementaridade da heterossexualidade. Quando há qualquer nível de descolamento, deve haver uma intervenção especializada, principalmente de algum especialista nas ciências psi, para restabelecer a ordem e a "coerência" entre corpo, gênero e sexualidade. É esse mapa que fornecerá as bases fundamentais para a construção do diagnóstico de gênero.

\footnotetext{
${ }^{3}$ Atualmente, Harry Benjamin International Gender Dysphoria Association chama-se World Professional Association for Transgender Health WPATH). Para uma sistematização da história da institucionalização da ransexualidade o espaço acadêmico e hospitalar, ver Berenice BENTO, 2006; Pierre Henry ASTEL, 2001; e Jorge LEITE JÚNIOR, 2011.

${ }^{4}$ WPATH, 2012. Para uma leitura do Standardt of Care (sétima versão), onsultar <www.wpath.org>.

${ }^{5} \mathrm{PSIQ}$ WEB, 2012.
} 
Nos três documentos de referência (DSM-IV, CID-10 e SOC), as pessoas transexuais são construídas como portadoras de um conjunto de indicadores comuns que as posicionam como transtornadas, independentemente das variáveis históricas, culturais, sociais e econômicas. Mas há algumas diferenças entre esses documentos. Para o SOC, "o transexual de verdade" tem como única alternativa, para resolver seus "transtornos" ou "disforias", as cirurgias de transgenitalização. Já no DSM-IV a questão da cirurgia é apenas tangenciada, sua preocupação principal está em apontar as manifestações do "transtorno" na infância, na adolescência e na fase adulta. Neste documento, não há diferenciação entre sexo, sexualidade e gênero. São os deslocamentos do gênero em relação ao sexo biológico os definidores do transtorno, pois o gênero normal só existe quando referenciado a um sexo genital que o estabiliza. O CID-10, por sua vez, não é um manual de orientação ou de indicadores diagnósticos, é, antes, uma convenção médica que estabelece as características das doenças e seus respectivos códigos utilizados e aceitos internacionalmente por médicos/as e outros/as operadores/as da saúde.

Em 1994, o Comitê do DSM-IV substituiu o diagnóstico de "Transexualismo" pelo de "Transtorno de Identidade de Gênero". ${ }^{\circ}$ Dependendo da idade, aqueles com uma

forte e persistente identificação com o sexo oposto e um persistente incômodo com seu sexo ou um sentimento de impropriedade dos papéis de gênero desse sexo passaram a ser diagnosticados como Transtorno de Identidade de Gênero na Infância (302.6), Adolescência e Adulto (302.85). ${ }^{7}$

Para as pessoas que não cumprem os critérios, o DSM-IV empregou o termo de "Transtorno de Identidade de Gênero Não Especificado (GID-Nos-302.6)". Os números representam os códigos que identificam internacionalmente os tipos de "transtornos de gênero".

A Classificação Estatística Internacional de Doenças e Problemas Relacionados com a Saúde (CID-10) apresenta os códigos e a tipificação da doença que devem estar presentes em todos os diagnósticos para que tenham validade legal. O "transexualismo", por exemplo, é definido como "transtornos da identidade sexual (F64.0)". Além "do transexualismo", há o "travestismo bivalente (F64.1), o transtorno de identidade sexual na infância (F64.2), outros transtornos da identidade sexual (F64.8), o transtorno não especificado da identidade sexual (F64.9)", ou seja, eliminou-se, em 1973, o "homossexualismo" do DSM ${ }^{8}$ e, em 1975, do CID-10, mas o que assistimos em seguida foi a uma verdadeira proliferação de novas categorias médicas que seguem patologizando comportamentos a partir do pressuposto heterormativo, que exige uma linearidade sem fissuras entre sexo genital, gênero, desejo e práticas sexuais. ${ }^{9}$

A patologização da sexualidade continua operando com grande força, não mais como "perversões sexuais" ou "homossexualismo", mas como "transtornos de gênero". Se o gênero só consegue sua inteligibilidade quando referido à diferença sexual e à complementaridade dos sexos, quando se produz no menino a masculinidade e na menina a feminilidade, a heterossexualidade está inserida aí como condição para dar vida e sentido aos gêneros.

\footnotetext{
- Segundo nota do comitê da APA, publicada em sua página eletrônica, transexualidade passará a ser nomeada, possivelmente, por "incongruência de gênero". Ver site <http://www.dsm5.org>.

${ }^{7}$ PSIQ WEB, 2012

8 Esta "postura será oficializada com o lançamento da terceira versão este manual (DSM-III), em 1980, já sem esta categoria" (LEITE JÚNIOR, 2011, p. 156).

9 Judith BUTLER, 2003.
} 
O sociólogo Giancarlo Cornejo, em sua autoetnografia queer, resgata as contínuas e persistentes avaliações às quais era submetido pela psicóloga da escola onde estudava, pois, sendo ele um "menino afeminado", era visto como uma criança com problemas, pelo menos no entendimento daquela profissional, assim como de alguns/mas professores/as do pequeno Giancarlo. "De fato", continua ele, "a psicóloga que mencionei me diagnosticou com um transtorno de identidade de gênero". ${ }^{10}$ Ser um menino afeminado patologizou seu corpo e mobilizou alguns adultos à sua volta na busca por uma possível e desejada "cura". O professor de Educação Física ofereceu-lhe atividades masculinizantes; o pai esforçou-se para que o garoto aderisse ao modelo de masculinidade viril que ele mesmo desempenhava; sua mãe carregou certa culpa, pois o corolário do diagnóstico do transtorno de gênero é justamente a culpabilização da mãe pelo seu amor excessivo. No melhor estilo stolleriano, como constata o próprio Giancarlo, ele não foi

o único patologizado por estes professores, psicólogas e psiquiatras, o foram também meus pais, e especialmente minha mãe. Figuras como as do "pai ausente" ou "mãe super protetora" não tardaram a aparecer como explicações de (pois teria que ser explicado) meu afeminamento."

Entretanto, conclui Cornejo, os esforços para "adequá-lo" a um suposto gênero correto foram vãos. Professores, psicólogos e seus próprios pais não lograram chegar a um diagnóstico preciso e, assim, "corrigi-lo".

Diante dessas complexas experiências, como são complexas as experiências humanas em geral, o saber médico não pode justificar os "transtornos" por nenhuma disfunção biológica. Em última instância, são as normas de gênero que contribuirão para a formação de um parecer médico sobre os níveis de feminilidade e masculinidade presentes nos demandantes. Serão elas que estarão sendo citadas, em séries de efeitos discursivos que se vinculam às normas, quando, por exemplo, se julga ao final de um processo se uma pessoa é um(a) "transexual de verdade". Não existem testes clinicamente apropriados e repetíveis ou testes simples e sem ambiguidades. O que assusta é perceber que tão pouco conhecimento, credenciado como científico, tenha gerado tanto poder.

\section{Resistência contra a patologização: o gênero politizado}

Desde a primeira publicação, em 1952, do DSM é a primeira vez que ocorre um movimento globalizado pela retirada da transexualidade do rol das doenças identificáveis como transtornos mentais. De forma rizomática, o movimento Pare a Patologização! vem conseguindo adesões em vários países, o que revela não só a capacidade de resistência de múltiplas vozes que se unem contra o poder da APA, mas também o alcance e o poder desta instituição.

Atualmente, são mais de 100 organizações e quatro redes internacionais na África, na Ásia, na Europa e na América do Norte e do Sul que estão engajadas na campanha pela retirada da transexualidade do DSM e do CID. As mobilizações se organizam em torno de cinco pontos: 1) retirada do Transtorno de Identidade de Gênero (TIG) do DSM-V e do CID11 ; 2) retirada da menção de sexo dos documentos oficiais; 3) abolição dos tratamentos de normalização binária para pessoas intersexo; 4) livre acesso aos tratamentos hormonais e às cirurgias (sem a tutela psiquiátrica); e 5) luta contra a transfobia, propiciando a educação e a inserção social e laboral das pessoas transexuais.

${ }^{10}$ Giancarlo CORNEJO, 2011 , p. 85. Todas as traduções do texto de Cornejo foram feitas pelas autoras deste artigo. 
As primeiras manifestações nesse sentido ocorreram em Madri, Barcelona e Paris, em 2007. No ano seguinte, mais cidades tiveram mobilizações contra a patologização transexual. Em 2009, os desdobramentos da Campanha se estenderam. O mês de outubro daquele ano foi um marco nesse sentido, quando foram realizadas em 29 cidades de 17 países iniciativas pela eliminação do transtorno de identidade de gênero dos manuais internacionais de diagnóstico. As atividades daquele ano tiveram origem em Paris, com a iniciativa do Coletivo Manis de Visibilidade Trans (também conhecido como Existrans).

Desde o ano de 2010 a adesão à Campanha vem se multiplicando no Brasil. Entre essas manifestações destacam-se a publicação de um manifesto e a produção de material de divulgação da Campanha pelo Conselho Regional de Psicologia de São Paulo, ${ }^{12}$ mostras de filmes, debates e seminários em universidades, além da redação e da publicização de manifesto ${ }^{13}$ assinado por ativistas, professoras/es e cientistas de diversos países que se somaram à campanha Stop Trans Pathologizantion 2012.

Ainda que algumas/uns ativistas temam pela perda de direitos conquistados como, por exemplo, no Brasil, a garantia de acesso gratuito ao processo transexualizador pelo Sistema Único de Saúde (SUS), ${ }^{14}$ acreditamos que a patologização não garantiu direitos de fato, mas impôs um modelo para se pensar a transexualidade como experiência catalogável, curável e passível de normalização. Tratou-se até aqui de um processo que qualificou alguns saberes científicos como os únicos capazes de dar respostas acertadas às vivências que desafiam as normas de gênero. Processo que, por outro lado, autoriza o tutelamento dos corpos e das subjetividades de pessoas que se reconhecem como transexuais. Autonomia reivindicada pelo sociólogo espanhol e ativista trans Miguel Missé, quando escreve que

lutar pela despatologização é defender que nossas identidades fazem parte da diversidade e que temos direito a modificar nosso corpo quando assim decidirmos. Reivindicar um livre acesso aos hormônios ou às cirurgias é a parte central da luta, não um detalhe, não é uma segunda etapa da luta: é uma luta em si mesma. ${ }^{15}$

\section{Quem são os/as normais e os/as transtornados/as de gênero?}

A campanha pelo fim do diagnóstico de gênero tem que enfrentar argumentos que utilizam como estratégica discursiva a diferença sexual dos corpos, entendida como natural, leia-se, normal e imutável. Por esse prisma, as identidades derivariam dessa base natural: o corpo. Os corpos sexuados, ou não, já nos mostraram algumas/alguns estudiosas/os como Thomas Laqueur, ${ }^{16}$ estão inseridos em processos históricos de classificação, significação e intervenção. Assim, pessoas cujo gênero - conceito que também tem sua historicidade e tem sido campo de disputa teórica entre diferentes áreas de conhecimento, como nos mostra Anne Fausto-Sterling ${ }^{17}$ - não está em conformidade com o sexo genital precisariam de tratamento. Mais que isso, deveriam ser tuteladas.

\footnotetext{
11 CORNEJO, 2011, p. 88.

12 O material e o Manifesto podem ser acessados em <www.crpsp.com>.

13 O referido manifesto pode ser lido na íntegra no seguinte site: <http://www.cchla.ufrn.br/bagoas/ v04n05art15 manifesto.pdf $>$.

${ }^{14}$ Portaria $G M$ n. 1.707, de 18 de agosto de 2008. Para uma discussão mais aprofundada, ver Tatiana LIONÇO, 2009

${ }^{15}$ Miguel MISSÉ, 2011 , p. 270, tradução nossa.

16 Thomas LAQUEUR, 2001

17 Anne FAUSTO-STERLING, 2001.
} 
O exercício que fazemos, a seguir, busca sintetizar um esforço teórico-político em apontar as fragilidades e as lacunas dos argumentos em defesa da patologização do gênero. Ressaltamos a preferência, aqui, por nomear "patologização do gênero" em vez de "psiquiatrização do gênero", por entendermos que há um conjunto de saberes polimorfos que se articulam para produzir as normas e os normais de gênero. Embora o DSM seja um documento de caráter psiquiátrico, ele consegue se materializar em políticas do corpo nos programas de identidade de gênero e em políticas de Estado, uma vez que compartilha com os outros saberes as mesmas bases fundacionais definidoras do gênero.

\section{Argumento I - Diferença natural entre os gêneros}

TRANSEXUAIS E TRAVESTIS SÃO DOENTES PORQUE OU SE NASCE HOMEM OU SE NASCE MULHER.

Este argumento circula amplamente em todas as esferas e relações sociais. Contudo, não se pode identificá-lo como pertencente exclusivamente ao chamado senso comum. Aqui, senso comum e pensamento científico hegemônico se retroalimentam, tornando difícil identificar onde começa um e termina outro. No presente, o senso comum, que também muda seus preceitos uma vez que é historicamente informado, afirma o dimorfismo entre homens e mulheres baseando essa argumentação na observação e referendando-a nas ciências biológicas, como aquelas que já ofereceram provas indiscutíveis da radical diferença sexual que separa os corpos sexuados. O pensamento científico hegemônico se apropria das recorrências observáveis nas relações entre os gêneros para conferir cientificidade aos seus achados, reforçando circularmente a diferença sexual natural, subsumindo nessas "verdades" os aspectos culturais e simbólicos que constituem nossas percepções sobre corpos, gêneros, órgãos e fluidos.

Certamente a ideia de que somos aquilo que nossos hormônios determinam produz certa segurança ontológica, principalmente para aqueles/as que lutam para conseguir um diagnóstico de transtorno de identidade de gênero. Dessa forma, ter uma doença, ou ser um transtornado/a de gênero, pode apresentar-se com uma força quase libertadora para algumas pessoas, justamente por situar a experiência trans fora da agência e da capacidade do sujeito em produzir significados múltiplos para o gênero, a sexualidade e o corpo.

Por essa perspectiva, raramente se considera, como o faz Fausto-Sterling, que

nossos corpos são complexos demais para dar respostas claras sobre a diferença sexual. Quanto mais procuramos uma base física simples para o "sexo" mais claro fica que o "sexo" não é uma categoria física pura. Aqueles sinais e funções corporais que definimos como masculinos e femininos já vêm misturados em nossas idéias sobre o gênero. ${ }^{18}$

O texto citado elabora uma criteriosa e bem fundamentada discussão epistemológica, socioantropológica e histórica das múltiplas configurações e performances de gêneros e de práticas eróticas em outras sociedades e em nossa própria, e ajuda a sustentar nossa tese de que o gênero tem menos a ver com natureza do que com relações de poder.

Discutir gênero é se situar em um espaço de lutas marcado por interesses múltiplos. A natureza do gênero é ser desde sempre cultura. Nas últimas décadas, essa disputa interna e externa ao mundo acadêmico ficou explicitada. Cientistas sociais, historiadoras/es, filósofas/ os e alguns setores do ativismo LGBTTI (lésbicas, gays, bissexuais, travestis, transexuais e intersexos) vêm produzindo discursos contra-hegemônicos ao poder/saber da biomedicina. ${ }^{19}$

${ }^{18}$ FAUSTO-STERLING, 2001, p. 19.

19 Para uma estimulante discussão sobre como pessoas intersexuais têm se apropriado e enfrentado os discursos médicos, ver Paula MACHADO, 2012. 
A tensão desse debate é potencializada quando se faz um recorte vinculando-o às questões das pessoas transexuais e travestis. Nesse momento, emergem outras configurações discursivas apresentadas a favor da manutenção do gênero como categoria diagnóstica.

\section{Argumento II - A visão suicldógena}

NÃO SE PODE RETIRAR A OBRIGATORIEDADE DA TERAPIA PSICOLÓGICA OU FLEXIBILIZAR O PROTOCOLO. HÁ RELATOS DE PESSOAS TRANSEXUAIS QUE SE SUICIDARAM PORQUE FIZERAM AS TRANSFORMAÇÕES CORPORAIS E DEPOIS SE ARREPENDERAM. ESSAS CIRURGIAS SÃO IRREVERSÍVEIS.

As pesquisas de Arán, ${ }^{20}$ Bento, ${ }^{21}$ LionçO ${ }^{22}$ e Teixeira ${ }^{23}$ mostram a fragilidade dessa prédica que anuncia as pessoas transexuais e travestis como potencialmente suicidas. Esse argumento sustenta a defesa da necessidade de um protocolo rígido que obriga as pessoas trans a realizarem acompanhamento terapêutico como forma de protegê-las de seus próprios desejos. Procedimento que, por meios institucionais, escamoteia a posição hegemônica de que essas pessoas são transtornadas, portadoras de subjetividades, desconectadas com a realidade e, portanto, sem condições psíquicas de administrar suas escolhas. Essa é uma estratégica discursiva que retira a autonomia e não reconhece a condição de sujeitos das pessoas transexuais e travestis.

Parece uma contradição que qualquer psicólogo ou psicanalista, minimamente consciente dos significados da aliança terapêutica, defenda a obrigatoriedade da terapia; daí o crescente número desses/as profissionais que se somam à luta pela despatologização do gênero em todo o mundo e que passam a estabelecer uma importante discussão e disputa interna ao seu campo de saber.

A questão do protocolo utilizado nos centros de saúde que fazem as cirurgias de transgenitalização adquire para nossa discussão uma importância central. Uma vez definido que o gênero é uma categoria medicalizável, o passo seguinte será estabelecer os mecanismos para curar suas "disfunções". O protocolo que orienta as políticas públicas para o atendimento à saúde da população travesti e transexual segue inteiramente os cânones da APA e do CID.

Pelo protocolo, todo "candidato" que queira realizar a cirurgia deve fazer terapia psicológica (por um tempo mínimo de dois anos), realizar o teste de vida real (usar as roupas do gênero identificado diariamente), tomar hormônios, realizar os testes de personalidade (Rorschach, MMPI) e fazer os exames laboratoriais de rotina.

Se partirmos do pressuposto de que há múltiplas possibilidades de experiências e práticas de gênero, e de que as pessoas que solicitam alterações corporais ou desejam migrar legalmente de um gênero imposto para outro com o qual se identificam são sujeitos capazes de conferir sentido para essas transformações, não há justificativa para definir um protocolo fundamentado no transtorno mental. Questionar o protocolo, nos termos em que vem sendo implementado, é encarar a questão da patologização do gênero e colocá-lo na arena de debates, situando-o como categoria científica, por isso mesmo, histórica, o que significa considerar também seu caráter político. ${ }^{24}$

\footnotetext{
${ }^{20}$ Márcia ARÁN, 2005 e 2006.

${ }^{21}$ BENTO, 2006 e 2008.

22 LIONÇO, 2009. ${ }^{23}$

Flávia TEIXEIRA, 2009

${ }^{24}$ Certamente para algumas pessoas transexuais e travestis a escuta terapêutica é importante. Mas o tempo da terapia e a escolha do/a terapeuta devem ser questões (e todas as demais) fundamentadas no reconhecimento pleno da capacidade do sujeito que vive a experiência transexual e travesti em decidir, inclusive se em determinados momentos precisa da ajuda especializada para decidir, aliás, como tantos outros sujeitos que recorrem às ciências psi.
}

576 Estudos Feministas, Florianópolis, 20(2): 569-581, maio-agosto/2012 
Nesse campo de disputas os inúmeros protocolos alternativos que foram formulados pelo movimento transexual em diversos países não adquiriram a legitimidade dos aplicados nos centros de saúde que atendem essa população. Nesses documentos alternativos o princípio estruturante está no reconhecimento da condição de sujeito das pessoas transexuais e travestis, conferindo, portanto, protagonismo a esses sujeitos.

Por tudo isso, a questão do suicídio nos parece muito mais uma retórica da vitimização que autoriza que se continue medicalizando aquelas/es que não cumprem as expectativas de gênero anunciadas pela pretensa verdade estabelecida pelo sexo genital.

\section{Argumento III - Concessões estratégicas}

SE A TRANSEXUALIDADE E A TRAVESTILIDADE NÃO FOREM CONSIDERADAS DOENÇAS, O ESTADO NÃO CUSTEARÁ AS DESPESAS COM PROCESSOS DE TRANSFORMAÇÕES CORPORAIS.

Há um grupo considerável que defende esta estratégia, mas que, ao ser dividido, se verificam interesses diferentes. Para as pessoas transexuais e travestis que precisam utilizar os serviços públicos para realizarem determinadas transformações corporais, é uma preocupação a retirada do caráter de transtorno das classificações e definições referentes a essas vivências. Mas há os que defendem o diagnóstico de gênero e que se ancoram oportunisticamente no argumento do acesso aos serviços de saúde, principalmente aquelas/ es que operam capilarmente o DSM, ou seja, os especialistas que são acionados para produzir o parecer final sobre a demanda de cirurgia de transgenitalização (enfermeiras, psicólogos, endocrinologistas, fonoaudiologistas, cirurgiões plásticos, psiquiatras, assistentes sociais).

No entanto, independentemente do interesse que motiva a defesa do diagnóstico de gênero, nota-se uma inversão à lógica do pertencimento a uma comunidade chamada Estado-Nação. Os interesses hegemônicos do Estado passam a ser defendidos como verdades a-históricas e a biopolítica passa a ser naturalizada por um discurso de atemporalidade.

Se, para o Estado, os/as normais de gênero são aqueles/as que têm uma correspondência entre genitália, performance e práticas eróticas e se essa definição gera um modus operandi que exclui sujeitos que estão nos seus marcos, estamos diante de uma contradição com sua própria definição universalizante. A resposta para resolver essa contradição nos limites do DSM é a inclusão excludente. O silêncio diante de uma produção e reprodução de uma cidadania precária e deficitária, intencionalmente implementada pelo Estado, nos retira da posição de vítimas para a de cúmplices. Concordar que o gênero continue sendo diagnosticado, em vez de questionado, é permitir que os seres construídos como abjetos devessem continuar habitando as margens do Estado.

O Estado ganha sua concretude nas ações de sujeitos históricos. Fazemos o Estado a cada ato em que o experienciamos. Ele não é um ente substantivado, uma força abstrata que paira sobre nossas cabeças e que tem o poder absoluto e não está acima do mundo da vida.

Por que reforçamos uma concepção de Estado que prioriza as dinâmicas, as práticas, as disputas? Para nos contrapor ao argumento derrotista, que diz que retirar o gênero do DSM é desobrigar o Estado de custear os processos de transformações corporais. Estamos, portanto, produzindo um contradiscurso, aquele que analisa o Estado como uma entidade substantiva e metafísica. De onde vem o argumento que condiciona o acesso ao cuidado integral da saúde das pessoas trans ao parecer médico-psiquiatra de transtornado de gênero? Elaborar uma resposta para essa questão e enfrentar o exercício desconstrutivista, 
nos termos de Derrida. Assim, seria possível pôr em evidência o terrorismo discursivo que sustenta a "cidadania cirúrgica". ${ }^{25}$

\section{Argumento IV - A autoridade científica}

Por fim, há quem se fie no argumento da autoridade científica para defender o diagnóstico de gênero: afinal, se está no DSM-IV, no CID-10 e no SOC é porque está provado cientificamente que há os normais de gêneros e doentes. Será?

Porém, os princípios científicos de testabilidade e verificabilidade reivindicados por documentos como o DSM-IV podem ser questionados em cada uma das classificações ali apresentadas. No caso da transexualidade ou nos chamados "transtornos de identidade de gênero", a pretensão de cientificidade não se sustenta. Basta que analisemos um excerto referente a "Achados laboratoriais associados", constante do referido manual. Nele se lê que

não existe qualquer teste diagnóstico específico para o Transtorno da Identidade de Gênero. Na presença de um exame físico normal, geralmente não se indica o cariótipo de cromossomas sexuais e avaliações de hormônios sexuais. A testagem psicológica pode revelar identificação ou padrões de comportamento do gênero oposto. ${ }^{26}$

O SOC também reconhece limitações de um conhecimento cientificamente comprovado por testes laboratoriais para produção do diagnóstico de "disforia de gênero", mas alimenta a esperança de que as incertezas clínicas possam resolver-se no futuro por meio da investigação científica ${ }^{27}$ Afirmação risível, não fossem suas consequências graves nas vidas de inúmeras pessoas.

O que temos de "científico" é a definição de transtornos de gênero ou disforia de gênero estabelecendo protocolos universalizantes, definindo a normalidade de gênero, orientando e autorizando intervenções para, ao fim, se reconhecer anemicamente que não há confiabilidade em suas afirmações.

Por fim, chegamos ao verdadeiro conteúdo do DSM-IV: é um texto que materializa uma visão cultural hegemônica e singular de gênero, mas que, contraditoriamente, consegue seu êxito por apresentar-se como universal porque tem como aliada a retórica da cientificidade de seus achados. Portanto, a defesa da diferença sexual como dado primeiro para se definir o gênero é uma construção de gênero. É preciso reafirmar que o DSM-IV, o CID-10 e o SOC são falaciosos e produtores institucionais de identidades abjetas. Quem formula esses códigos é um grupo fechado de especialistas orientados pelos preceitos heteronormativos que, aliás, têm fundamentado a ciência ocidental moderna.

Sobre a falácia de cientificidade do diagnóstico de gênero, Pau Crego Walters afirma:

O discurso psiquiátrico parte da noção de que o diagnóstico é o resultado do conhecimento produzido através do método científico. No entanto, se o método é tão confiável, porque todos nós, pessoas transexuais, vivemos nosso gênero de maneira tão distinta? Se há uma condição congênita ou biológica para a suposta "transexualidade", como se explica, então, que alguém decida ser trans aos 14 anos e outras pessoas aos 40 e outra aos 80 ? E como explicar as diferenças na maneira de viver o gênero - e os trânsitos entre todos estes - nas diferentes classes sociais? ? $^{28}$

\footnotetext{
${ }^{25}$ Mauro CABRAL, 2010, p. 220.

${ }^{26}$ PSIQ WEB, 2012.

${ }^{27}$ WPATH, 2012.

${ }^{28}$ Pau Crego WALTERS, 2011 , p. 249.
} 


\section{Perguntas impertinentes para reflexões necessárias}

Por que diagnosticar o gênero? Quem autoriza psicólogos, psiquiatras, endocrinologistas e outras especialidades que fazem parte das equipes multidisciplinares a avaliarem as pessoas transexuais e travestis como "doentes"? Se não existe nenhum exame clínico que conduza a produção do diagnóstico, como determinar a ocorrência do "transtorno"? Quais e como estabelecer os limites discerníveis entre "os transtornados de gênero" e "os normais de gênero"?

O único mapa seguro que guia o olhar do médico e dos membros da equipe são as verdades estabelecidas socialmente para os gêneros, portanto estamos no nível do discurso. Não existe um só átomo de neutralidade nesses códigos. Estamos diante de um poderoso discurso que tem como finalidade manter os gêneros e as práticas eróticas prisioneiras à diferença sexual.

A campanha Pare a Patologização! tem um papel histórico de produzir e aglutinar forças na luta pela desnaturalização do gênero e, certamente, as mobilizações e as iniciativas que acontecerão em diversas partes do mundo produzirão efeitos múltiplos e rizomáticos. Certamente, a APA terá que se posicionar de forma mais transparente e contínua sobre os interesses que a fazem seguir operando uma categoria cultura como categoria nosológica.

\section{Referências}

APA. DSM-5. Disponível em: <http://www.dsm5.org > . Acesso em: 10 mar. 2010.

ARÁN, Márcia. Transexualismo e cirurgia de transgenitalização: biopoder/biopotência. Brasília: Série Anis, 2005.

. "A transexualidade e a gramática normativa do sistema sexo-gênero". Ágora: Estudos em Teoria Psicanalítica, Rio de Janeiro, v. 9, n. 1, p. 49-63, 2006.

BENJAMIN, Henry. "Transvestism and Transsexualism." Internacional Journal of Sexology, v. 7, n. 1, 1953.

El fenómeno transexual. Sevilla: [s.n.], 2001.

BENTO, Berenice. A (re)invenção do corpo: sexualidade e gênero na experiência transexual. Rio de Janeiro: Garamond; Clam, 2006.

. O que é transexualidade. São Paulo: Brasiliense, 2008 (Coleção Primeiros Passos).

BIAU, Camila. Além das 7 cores: um documentário queer. Projeto experimental apresentado como exigência parcial para obtenção do título de Bacharel em Comunicação Social, Habilitação em Rádio e Televisão, ao Departamento de Comunicação Social da Faculdade de Arquitetura, Artes e Comunicação da Universidade Estadual Paulista Júlio de Mesquita Filho. Bauru, 2011.

BRASIL. Ministério da Saúde. Portaria n. 1.707/GM. Brasília, 19 ago. 2008a.

. Secretaria de Atenção à Saúde. Portaria n. 457/SAS. Brasília, 20 ago. 2008b.

BUTLER, Judith. Problemas de gênero: feminismo e subversão da identidade. Rio de Janeiro: Civilização Brasileira, 2003.

. Undoing Gender. New York: Routledge, 2004.

CABRAL, Mauro. "Pensar la intersexualidad, hoy". In: MAFFIA, Diana (Comp.). Sexualidades migrantes: género y transgénero. Buenos Aires: Feminaria, 2003. p. 117-126.

(Org.). Campaña por la convención de los derechos sexuales y los derechos reproductivos. Lima: Fundación Ford, 2004. (Séries para el Debate, n. 3).

"En estado de excepción: intersexualidade e intervenciones sociomédicas". In: CÁCERES, Carlos F. et al. Sexualidad, estigma y derechos humanos: desafíos para el acceso a la salud en América Latina. Lima: Faspa; UPCH, 2006. p. 220-222. 
"Relatório". In: ARILHA, Margareth; LAPA, Thaís de S.; PISANECHI, Tatiane C. Transexualidade, travestilidades e direito à saúde. São Paulo: CCR, 2010, p. 210.

CASTEL, Pierre Henry. "Algumas reflexões para estabelecer a cronologia do 'fenômeno transexual (1910-1995)'”. Revista Brasileira de História, São Paulo, v. 21 , n. 41, 2001. p. 77-111.

CCHLA. Manifesto. Transexualidade não é doença! Pela retirada da transexualidade do DSM e do CID! Disponível em: <http://www.cchla.ufrn.br/bagoas/v04n05art15_manifesto.pdf>. Acesso em: 10 mar. 2012.

CONSELHO FEDERAL DE MEDICINA. Resolução n. 1.482, de 1997. Brasília, 1997.

Resolução n. 1.652, de 2002. Brasília, 2002.

CORNEJO, Giancarlo. "La guerra declarada contra el niño afeminado: una autoetnografía queer". Iconos: Revista de Ciencias Sociales, n. 39, p. 79-95, 2011.

CRP. Disponível em: <http://www.crpsp.org.br/portal > . Acesso em: 10 mar. 2010.

FAUSTO-STERLING, Anne. "Dualismo em duelo". Cadernos Pagu, Campinas: Núcleo de Estudos de Gênero - Pagu, n. 17/18, p. 9-79, 2001.

LAQUEUR, Thomas. Inventando o sexo: corpo e gênero dos gregos a Freud. Rio de Janeiro: Relume-Dumará, 2001.

LEITE JÚNIOR, Jorge. Nossos corpos também mudam: a invenção das categorias "travesti" e "transexual" no discurso científico. São Paulo: Annablume, 2011.

LIONÇO, Tatiana. "Atenção integral à saúde e diversidade sexual no Processo Transexualizador do SUS: avanços, impasses, desafios". Physis, Rio de Janeiro, v. 19, n. 1 , p. 43-63, 2009.

LOTHSTEIN, Leslie. Female-to-Male Transsexualism: Historical, Clinical and Theoretical Issues. Boston: Routledge \& Kegan Paul, 1983.

MACHADO, Paula S. "Intersexualidade, intersexualidades: notas sobre alguns desafios teóricos, metodológicos e políticos contemporâneos". In: MISKOLCI, Richard; PELÚCIO, Larissa (Org.). Discursos fora da ordem: deslocamentos, reinvenções e direitos. São Paulo: Annablume; Fapesp, 2012. p. 179-196.

MARTÍNEZ-GUZMÁN, Antar; MONTENEGRO, Marisela. "Producciones narrativas: transitando conocimientos encarnados". In: MISSÉ, Miguel; COLL-PLANAS, Gerald. El gênero desordenado: criticas em torno a la patologización de la transexualidad. Barcelona/ Madrid: Egales, 2011.

MISSÉ, Miguel. "Epílogo". In: MISSÉ, Miguel; COLL-PLANAS, Gerald. El gênero desordenado: criticas em torno a la patologización de la transexualidad. Barcelona/Madrid: Egales, 2011. p. 265-275

MISSÉ, Miguel; COLL-PLANAS, Gerald. El gênero desordenado: criticas em torno a la patologización de la transexualidad. Barcelona/Madrid: Egales, 2011.

PSIQ WEB. Disponível em: <http://www.psiqweb.med.br/site> . Acesso em: 10 mar. 2012.

RUSSO, Jane A. "Do desvio ao transtorno: a medicalização da sexualidade na nosografia psiquiátrica contemporânea". In: PISCITELLI, Adriana et al. Sexualidade e saberes: convenções e fronteiras. Rio de Janeiro: Garamond, 2004. p. 81-94.

STONE, Sandy. "El imperio contraataca: un manisfiesto postransexual". In: CABRAL, Mauro. (Org.). Campaña por la convención de los derechos sexuales y los derechos reproductivos. Lima: Fundación Ford, 2004. p. 13-32. (Séries para el Debate, n. 3).

TEIXEIRA, Flávia B. Vidas que desafiam corpos e sonhos: uma etnografia do construir-se outro no gênero e na sexualidade. Tese (Doutorado em Filosofia e Ciências Humanas) Instituto de Filosofia e Ciências Humanas, Universidade Estadual de Campinas, Campinas, 2009. 
WALTERS, Pau Crego. "Construir lo que somos". In: MISSÉ, Miguel; COLL-PLANAS, Gerald. EI gênero desordenado: criticas en torno a la patologización de la transexualidad. Barcelona e Madrid: Egales, 2011. p. 248-252.

WPATH. World Professional Association for Transgender Health. Disponível em: <http:// www.wpath.org >. Acesso em: 10 mar. 2012.

\section{Depathologization of the Genre: The Politicization of Abject Identities}

Abstract: Despite the social and political changes in respect of transsexualities and tranvestilities, they are still considered by the APA (American Psychiatric Association) and by the WHO (World Health Organization) as mental disorders. These organizations will disclose in 2013 the new versions of the DSM (Diagnostic and Statistical Manual of Mental Disorders - APA) and the ICD (International Code of Illness-WHO). This has mobilized trans activists claiming the withdrawal of transsexuality from the list of diseases considered as mental disorders. The Stop Trans Pathologization (Stop Pathologizing!) has become a global campaign, reaching 29 countries by early 2012. In this article, we will discuss some initiatives within this campaign and review the gender ideology present in the DSM and the ICD which incorporate the genre as a diagnostic category. Finally, we will present arguments against the gender diagnosis.

Key Words: Trans Identities; Stop Pathologizing Campaign; Gender; Sexuality. 